\title{
The Evolution of an Education Journal: A Genre Study
}

\author{
Anthony Paré \\ McGill University \\ Rosanne Roy \\ California State University, Stanilaus
}

This article reports on a study of the evolution of an education joumal over a 43-year period. The journal began life in 1954 as The Slow Learning Child, became The Exceptional Child in 1976, and continues today as The International Journal of Disability, Development, and Education. The changing title itself suggests an evolution in consciousness and constituency that provides the background for the study. Despite an initial determination to serve both university-and school-based educators, a rhetorical analysis of the joumal's changing discourse demonstrates a gradual shift away from the classroom and the concerns of practitioners and toward the discourse of experimental research and the knowledge it produces.

Cet article rend compte d'une étude portant sur l'évolution d'une revie consacrée à l'éducation pendant 43 ans. Parue en 1954, sous le titre The Slow Learning Child [L'apprenant lent], la revue s'est appelée ensuite, à partir de 1976, The Exceptional Child [L'enfant exceptionnel] et elle continue à paraitre aujourd'hui, sous le nom de The International Journal of Disability, Development, and Education [Journal international des déficiences, du développement et de l'éducation]. Ce changement de titre lui-même révèle une évolution des idées et de la clientèle, laquelle sert de toile de fond à l'étude présentée. Malgré l'intention initiale de la revue d'être au service des formateurs des écoles et des universités, l'analyse des changements au niveau du discours montre un éloignement progressif par rapport à la salle de classe et aux préoccupations des praticiens et un rapprochement vers la recherche expérimentale et le genre de connaissance qui en découle. 
Research and teacher talk define themselves against each other instead of in mutual support.

(Charles Bazerman, 1994, p. 4)

Like tools, proverbs (and other discourses) are marked by uses; they offer to analysis the imprints of acts or of processes of enunciation.

(Michel de Certeau, 1984, p. 21)

Professional scientific and academic journals offer ideal sites for a form of rhetorical archaeology that seeks to identify and explain the cultural forces that shape a community's texts and textual practices over the course of their development. Initially, in response to a perceived need for a specialized discourse, a group of people editors, writers, reviewers, readers - create a text that allows them to address their own topics in their particular rhetorical ways. The process is dialectic, and the emerging text in turn shapes and defines the nascent community and its culture. A study of the text over time reveals a community in a constant process of becoming.

The social motive that occasions the birth of journals is the apparent or felt need for a "forum": a public space for discussion. "The forum," explains Porter (1992), "is a trace of a discourse community, a defined place of assembly or means of publication for discourse communities. Each forum has a distinct history and rules governing appropriateness to which members are obliged to adhere" (p. 108). As time passes, the forum undergoes physical and rhetorical change as new people, practices, rules, and topics enter and reshape its space; the result is that the issues of a journal serve as a textual record of the growth and evolution of what Miller calls a "virtual community": "the community as invoked, represented, presupposed, or developed in rhetorical discourse" (Miller, 1994b, p. 73).

In this article, we take an archaeological approach to the study of an Australian journal dedicated to topics in the area of what is now called "special" or "inclusive" education. The journal began life in 1954 as The Slow Learning Child, became The Exceptional Child in 1976, and continues today as The International Journal of Disability, Development, and Education. The changing title itself suggests an evolution in consciousness and constituency that provides the background for our investigation. To explore in some detail the dynamics of that evolution, we looked at textual, linguistic, and rhetorical features of the journal: print size, font, graphics (i.e., tables, charts, figures), citation practices, register, diction, introductions, conclusions, and so on. In this article we speculate outward from those features to the social contexts the journal both served and shaped. Our questions are broad: What are the observ- 
able signs of change in a professional journal over time? What forces or factors appear to motivate change? What do those changes imply about the community and culture in which the journal serves as a forum?

Such questions are critical in the ongoing attempt to understand the role and function of genres in the formation of culture. Genre researchers are eavesdroppers on what Bakhtin calls "a multiplicity of social voices," or "the rivulets and droplets of social heteroglossia" (1981, p. 263). But we believe that there is something more at work in heteroglossia than the free play of voices; there is also a struggle to be heard, a "linguistic market" (Bourdieu, 1993), in which some voices are louder and more dominant than others. Within the multiplicity of voices, tensions exist:

In a society such as our own we all know the rules of exclusion. The most obvious and familiar of these concerns what is prohibited. We know perfectly well that we are not free to say just anything, that we cannot simply speak of anything, when we like or where we like; not just anyone, finally, may speak of just anything. (Foucault, 1972, p. 216)

However, though a sense of exclusion or regulation may be obvious, its origins and justification may not. We usually know when our voice is not welcome, but often cannot understand the source of or reason for our silencing.

Our study uncovers textual evidence of a dynamic that is familiar to anyone working in the field of education - the ideological tension between research and practice. Indeed, we believe our analysis reveals and helps explain typical patterns in the relationship between researchers and practitioners in many disciplines: a gradual widening of the space between theory and practice, between observation and action, between the general and the particular, and between academic and nonacademic worlds. In the development of this division, we see rules of exclusion coming into play, however unintentionally, and in this article we consider the reasons for and effects of those regulations.

\section{Genre as patterns in text and culture}

Our method of analysis consisted of a close reading of the journal, a reading guided by our belief that textual regularities are part of larger discourse patterns now widely known as genres. standardized social, textual, and rhetorical strategies that evolve within collectives in response to perceived exigencies. ${ }^{1}$ In taking the approach we adopt in this essay, we have accepted Carolyn Miller's (1994b) invitation to see genre "as an anthropologist sees a material artefact from an ancient civilization" (p. 69). In much the same way that archaeologists or classical anthropologists infer the 
life of communities from the nature and form of their surviving tools, we examine the journal as a textual artefact in order to make assumptions about the changing culture and conventions of its community. In other words, we exploit "the richness of genre as an archive of cultural imprints" (Giltrow, 1994, p. 174). ${ }^{2}$

A regular text, the discourse practices that produce and interpret it, the knowledge it creates, and the actions it engenders arise because a group of people sense a common or mutual need. The textual repetition both reflects and maintains a consistency in the community's discourse practices, as well as a degree of conservatism in its consciousness and ideology. In this definition of genre, we follow such theorists as Miller (1994a), Bakhtin (1986), Bazerman (1988), and those included in Freedman and Medway's (1994a; 1994b) collections who view genres as repeating patterns of similarity in the texts, contexts, and actions that comprise particular literate activities. Along with these theorists, however, we recognize that genres are not immutable; as Schryer (1994) says, genres are "stabilized-for-now or stabilized-enough sites of social or ideological action" (p. 108). Indeed, as we hope to show in what follows, genres are best viewed and understood paradoxically as consistent but changing: though similar enough in certain features of form and function to qualify as members of the same category, successive instantiations of particular genres in fact trace a trajectory of change, an evolution in the consciousness, epistemology, ideology, activity, and membership of communities.

Our analysis joins a handful of others (e.g., Bazerman, 1988; Berkenkotter and Huckin, 1995; Giltrow, 1994; Herrington, 1989) that seek to link developments in the textual and rhetorical features of non-literary genres to developments in the communities within which the genres operate. ${ }^{3}$ For scientific and academic journals, a type of reciprocity drives this text-context relationship: community creates text; text constructs community. More accurately, an emerging or nascent community with a perceived rhetorical need shapes discourse to address that need and that community. The original impetus may come from a single influential individual, as was the case with The Philosophical Transactions of the Royal Society of London (Bazerman, 1988), from a small group of like-minded or similarly inclined individuals, as with the newsletter (later journal) Reader (Berkenkotter and Huckin, 1995), or from emerging research or theory within already established communities, as with Research in the Teaching of English (Herrington, 1989). ${ }^{4}$ Once a forum is created, development proceeds through a parallel, mutual construction of forum and community: as the text begins to display preferred topics, intertextual allusions and references, privileged methodologies, an epistemological orientation, and other conventions, a community forms consisting of editors, authors, editorial boards, reviewers, and readers. The nature of that collective-its individual members and ethos - shapes and in turn is shaped by 
the nature of the journal. As Herrington (1989) notes, her study of the development of the journal Research in the Teaching of English reveals "a community constituting itself" (p. 118).

A second feature of this development is a movement away from an informal, interactive discourse toward a more formal, conventional, and declamatory discourse: in a sense, a movement from conversation to oration or from dialogue to monologue. As Bazerman (1988) reports, The Philosophical Transactions of the Royal Society of London began as correspondence between Henry Oldenburg and various scientists and grew into the first scientific journal in English. Likewise, Reader started life as a newsletter designed to produce a lively exchange among reader-response critics, and became a journal through three periods of development, the third of which "can best be described as a period of professionalization, that is to say, a period during which the routines of academic production that constitute normal science or scholarship become stabilized" (Berkenkotter and Huckin, 1995, p. 83). As our analysis demonstrates, The Slow Learning Child followed a similar developmental path: a need for rhetorical exchange within a possible or emerging community was perceived; the journal was begun as a forum for discourse considered relevant to that need; calls for exchange and interaction were published; a virtual community began to respond and to form around the journal; the community and journal developed a reciprocal relation, with each shaping the other; and, finally, the "routines of academic production" stabilized somewhat both the text and the context, including the journal's constituency.

Of greatest interest to us in our study of the journal's origins and evolution has been what appears to be a disjuncture between the expected or anticipated community - that is, the potential readers and writers originally perceived to have a rhetorical need-and the emerging virtual community-the readers and writers who in fact showed up in the forum. In fact, the metaphor of "evolution" may mislead, suggesting as it does a natural and agent-less process, since we believe our analysis shows a particular world view gradually shaping a discourse and ideology more suited to some members of the fledgling community than others. Specifically, we see a particular type of knowledge - experimentally produced research knowledge - and the discourse practices that generate such knowledge, gradually elevated over practitioners' knowledge. This, we propose, is a common rhetorical dynamic in the professional disciplines that consist of university-based researchers and theorists and workplace-based practitioners (e.g., education, social work, nursing; see Schryer [1994] for a discussion of competition between the genres of research and the genres of practice in veterinary medicine). More generally, our analysis demonstrates a politics of epistemology, in which a hierarchy of knowing is constructed through the social action of genre. 


\section{In the beginning ...}

The Slow Learning Child was the response in 1954 to a need perceived by members of the Faculty of Education of the University of Queensland. Chief among those faculty members was Fred Schonell, the first editor and a key figure in the journal's early years. In his inaugural editorial, Schonell explained "the purpose behind the idea of publishing a journal devoted to psychological and educational problems of slow learning children in Australia":

For several years now the Faculty of Education of the University of Queensland has conducted a number of in-service training courses dealing with the education of backward children. Teachers from the various States who attended these indicated that they had difficulty in obtaining continuous and systematic information on experimental work with backward children, on exact details of new teaching methods and on books and equipment especially suited to them and available in Australia. It was apparent too that teachers in any one State were not aware at times of the excellent work carried out in other States. In fact the short in-service courses often provided opportunities for teachers to exchange valuable information. $(1954 ; 1.1, \mathrm{p} .1)^{5}$

The journal's original (stated) motive, then, as conceived by university-based academics, was to provide classroom teachers with "continuous and systematic information" on research, teaching methods, and materials, as well as to offer a forum for the exchange of ideas among teachers. In addition, Schonell acknowledged that the problem of insufficient information "is not exclusive to Australian teachers of backward and subnormal children," and that journals in the U.S. and England addressed similar concerns; however, he argued that those journals "do not treat the problem a social and educational one - against an Australian background" (1954; 1.1, p.1). This dual emphasis - on teachers and on an Australian perspective - is reflected in the first issue of the new journal in articles on resources for handicapped children in Western Australia, a classroom approach used in the Australian state of New South Wales, and support available to parents across the country, and in a promise that future issues would "include a series of articles by headteachers of special schools or classes on details of organisation and methods of teaching in such schools or classes." In addition, Schonell writes that "the journal will require an Editorial Advisory Board representative of the various [Australian] states" $(1954 ; 1.1$, p.2). 
The positive response to The Slow Learning Child appears to have been a surprise. As reported in the journal's second editorial, Schonell and his colleagues had "considered that the 450 copies printed would be more than enough to meet the demand," but "the first issue is exhausted and still Subscriptions come in" (1954; 1.2, p.37). This second editorial also restates the commitment to teachers: "The policy outlined in our [first] issue is continued in this number. Emphasis is once more on articles which it is hoped will be of practical value to the special class teacher" (1954; 1.2, p. 37). To that end, there are two articles by classroom teachers, an article on teaching reading by an education faculty member, and another article by an education professor that asks "questions which every special class teacher ... must consider" (1954; 1.2, pp. 37-8). Furthermore, teachers are encouraged to contribute:

We would like to stress once more the importance we attach to the section "Notes From The Classroom". Here we hope to detail actual teaching methods and materials which teachers find useful in their everyday work. It is one of our main aims to spread information, to make the journal a means by which ideas can be communicated to others working in the field, a means by which suggestions and comments may be made, or questions asked.... Until we achieve this interchange of ideas and opinions we will not have entirely fulfilled our raison d'etre. $(1954 ; 1.2$, p. 38$)$

It is important to note in the excerpts above that teachers were identified as primary consumers and producers of the knowledge the journal sought to create. Schonell added "psychologists, guidance officers and others working in this special branch of education" (1954; 1.1, p. 1) to the list of potential readers in his first editorial, but the community Schonell and his colleagues envisioned appears to have been a mix of educational researchers and practitioners. (Later, an editorial noted that "[ $t$ ] here is of course no absolutely clear cut distinction between the two" [1957; 3.3, np].) A perceived information shor tage and lack of exchange among Australian teachers was the original motive or exigence that prompted the creation of The Slow Learning Child, and the first years of the journal are marked by repeated and increasingly more direct efforts to draw those teachers into the emerging virtual community:

The 'Slow Learning Child'... is intended primarily for teachers and others working with backward and subnormal children (1955; 1.3, np); 
It is the policy of this journal to provide for teachers, psychologists and others working with slow learning children (1957; 3.3, np);

It will still $\ldots$ be the aim of the Journal to maintain close association with the classroom and with the teacher $(1959 ; 6.1$, p. 3);

Once again the editors emphasize the desirability of literary contribution by practising teachers $(1962 ; 9.1$, p. 2$)$;

The Editors think that the first issue of a new volume is a good time to advise teachers - those most modest people publication-wise - that 'The Slow Learning Child' welcomes contributions from the teaching field $(1965 ; 12.1$, p. 2$)$;

What is lacking [in the journal], however, is Australian contributions from the practising teacher $(1966 ; 12.3$, p. 130$)$;

It is always gratifying to receive articles from practising teachers reporting on aspects of their work (1967; 13.3, p. 130);

Research for The Slow Learning Child need not be highly formalised. Class-room enquiry is very welcome (1968; 14.3, p. 130).

\section{What if they declared a forum and no one came?}

The Australian teachers for whom the forum was created apparently did not show up, or at least not in sufficient number or in the roles of research producers and consumers that were anticipated. An indication that the people who published the journal were uncertain of the nature and preferences of their readership and concerned about the contribution of teachers - "those most modest people publication-wise" - is a questionnaire that appears in 1960 (6.3). The editor of that issue, while acknowledging that increased circulation $(1,200$ by $1959 ; 6.1, \mathrm{p} .2)$ suggested that subscribers were satisfied, nevertheless wrote that "the time has come for a more direct consultation with our readers." He continued: 
With such a specialised audience as that reached by "The Slow Learning Child", it is obvious that the vast majority are concerned with some aspect of the education of educationally subnormal or retarded children. Although they may modestly deny that they are "experts", all must be to some extent knowledgeable. In a sense, therefore,"The Slow Learning Child" represents a forum for, or a means of communication between, members of a community who are linked by a common purpose. All of us, editors, editorial advisory board and subscribers, have our own individual experience, knowledge and views about the slow learner. $(1960 ; 6.3$, p. 130)

We believe that this passage is directed at teachers, whose "modesty" prevents them from reporting their work in the journal, and we believe it reflects a gap between the editors' frequently stated aspiration to create a particular type of community (with research-producing and -consuming Australian teachers as key constituents) and the developing virtual community, which our analysis (below) suggests quickly became international and university-based. This belief is further strengthened by the editorial of 6.3, which seems to reprimand non-contributing readers (the journal equivalent of Internet list lurkers): "Readers should not feel that the dissemination of knowledge must inevitably be a one-way stream. As members of this community, they have not only the opportunity, but to some extent a duty to share their knowledge and experience with others" (1960; 6.3, p. 130). Just who those guilty readers are, signalled already by the reference to "modesty" above, becomes clear in the subsequent passage - a direct appeal to teachers in Australia, Asia, and beyond:

We should like subscribers to feel that they can and should write to the editors if they have anything to offer which might be of interest to other readers. In many classrooms in Australasia as well as overseas, much classroom work of first rate quality is going on, but remains relatively unknown because in many cases the teacher concerned either underestimates the value of the original ideas he has introduced, or else his modesty is such that he does not consider that his work might be of interest to others; and moreover he hesitates to submit a written account to a university "learned journal". (1960; 6.3, pp. 130-31) 
Implied here is a failure to "achieve [the] interchange of ideas and opinions" that was the journal's original "raison d'etre" (1954; 1.2, p. 38). Instead, "a one-way stream" of knowledge dissemination had developed, apparently flowing from university-based researchers to classroom-based teachers. And although editorials, right up to the last issue of The Slow Learning Child, insist that "a journal beneficial to teachers and others who work with exceptional children ... continues to be the major aim of the editors" $(1975 ; 22.3, \mathrm{np})$, it becomes increasingly clear in the pages of the journal's first two decades that the Australian teachers who were expected to be its chief writers and readers had not materialized. In other words, a different community formed around and through the genre than was originally anticipated and, perhaps, desired. Beginning early in the journal's life, but most obviously after it became The Exceptional Child in 1976 (23.1), the discourse community appears to have been re-conceived: fewer and fewer calls are made to teachers and, as we demonstrate below, there are increasingly fewer publications by teachers. Finally, and currently, as The International Journal of Disability, Development and Education, the journal has become a forum for a global community of researchers in a wide variety of fields - education, of course, but also psychology, social work, physical and occupational therapy, and other disciplines.

Why did a genre that appeared initially to be designed specifically for the needs of the Australian classroom practitioner become instead a research journal? Is it that teachers are apathetic? Anti-research or anti-intellectual? Too preoccupied by the everyday demands of resource-poor, over crowded classrooms? Or did the evolving genre, despite the editors' frequent encouragements, really not respond to a social motive that teachers recognized? Were teachers invited into a forum that was inappropriate or irrelevant to their own needs?

We do not believe that the university-based faculty members who began the journal deliberately created a research forum for themselves and other academics, while saying they wanted to publish practitioner knowledge; in any case, intention is often not apparent in or recoverable from texts. However, our analysis does reveal a contradiction between the editors' stated intentions and the text they created. In what follows, we consider some of the subtle social, textual, and rhetorical factors that may have turned teachers away from the evolving genre. 


\section{Double messages}

\section{From Australia to the world}

Despite frequent, strong statements of commitment to teachers in the Australian context, The Slow Learning Child began early to reach outwards toward a wider, more diverse community. As mentioned above, the first editorial $(1954 ; 1.1)$ identified Australian teachers as primary members of the new journal's community, indicated the need for a discussion of special education "against an Australian background" (p. 1), and promised "an Editorial Advisory Board representative of the various [Australian] States" (p. 2), but it also promised "contributions from workers in the field in U.S.A. and Great Britain" and "research, practice and opinion [from] throughout the Commonwealth" (p. 2). The Australian perspective was widened almost immediately with the second issue, which included an article by a teacher from New Zealand and "a welcome to the newly formed editorial board [of] representatives of the various Australian States and of New Zealand" (1954; 1.2, p. 38); thereafter, the journal makes reference to an "Australasian" perspective. By 1.3, the journal's eventual international constituency began to develop, with the editorial admission that other countries, "particularly the United States, are well ahead of us in Australia" $(1954 ; 1.3$, p. 94) in the areas of training and research, and the inclusion of articles by an American and a Canadian academic.

The trend toward the global community that is reflected in the journal's current title continued through the early years, and by 1959 (6.1) the editors were able to boast that the journal's "geographical distribution covers most countries of Western Europe, all countries of the British Commonwealth, many parts of the United States of America, South-East Asian areas, Egypt and islands of the South Pacific" (p. 2). Moreover, following an acknowledgement of "the competent advice of the journal's Australasian Editorial Board," there is in that sixth anniversary issue:

an announcement of perhaps the most important development to date - the formation of an Overseas Editorial Board. The establishment of this Overseas Editorial Board means that in future the journal will have available to it greater representation than formerly of British, American and Western European thought in the educational and psychological field. (pp. 2-3) 
Those contributions, however, were apparently not to come from teachers in those other areas of the world, since classroom teachers were not represented on the newly formed Overseas Editorial Board. By 1966 (12.3), the editorial begins with this claim: "As usual, this journal has an international flavour - articles from Australia, the United States, Denmark and Germany" (p. 130). ${ }^{7}$

Throughout its middle years - from the late 60 's through its name change to The Exceptional Child $(1976 ; 23.1)$ and into the 80's - the journal offered an increasingly international selection of authors. This was especially true in the 80 's, and when Winifred Apelt - editor from 1981 to 1988 - resigned, a colleague saluted her:

Her enthusiastic promotion of the journal has changed its nature from one which reflected predominantly Australian views, to one which has a broader international appeal. This change in focus has led the editorial board to propose a change of name to reflect the increased representation of contributors from many nations and the international perspective provided by the articles published $(1988 ; 35.3$, p. 133).

By the next issue, the journal had become the International Journal of Disability, Development and Education. The inaugural editorial under that new title acknowledged "an obvious transition from what was a primary publication forum for Australian researchers and practitioners in special education to one which has attracted the interest of researchers and scholars from many countries." And, in promising continuity with the past, the editor appears to overlook the original commitment to practical knowledge: "The International Journal of Disability, Development and Education maintains the same aims as The Exceptional Child, that is, to publish original research reports and reviews" $(1989 ; 36.1, \mathrm{np})$.

The international nature of the journal became a focus for defining content and constituency after the name change, and frequent editorial reference is made to it (in, for example, $41.3,42.1,42.2,43.3)$. In 1995, the editor reports that the 110 articles published since the name change were written by authors from 22 different countries (42.2, p. 91), and subscriptions in late 1997 were held in 28 countries, with the U.S. having more subscribers than Australia (Sigafoos, October 1997, personal communication). Perhaps the most visible and dramatic sign of the transformation from an Australian to an international forum was the 1996 move of the journal's publication office from its original University of Queensland's home to the Carfax Publishing Company in the U.K. As we demonstrate in the following section, this move toward an international audience parallelled a shift in focus from knowledge gained through classroom practice to knowledge gained through experimental research. 


\section{From practice to research}

We have argued above that the original editors imagined that teachers would be both consumers and producers of the knowledge created through the journal. At least, that is what the frequent requests for teacher contributions suggest. However, the editors envisioned a community that included more than teachers, and the first editor invited "psychologists, guidance officers and others" (p. 1) into the forum that he and his colleagues had created. Moreover, despite occasional protests to the contrary, it seems clear that from the beginning two types of knowledge were anticipated: practical knowledge and research knowledge. As early as 1.2, after stressing the importance of reports on "actual teaching methods and materials," the editorial places teachers clearly in the role of research consumers:

we aim in future to change slightly the present emphases in the journal. It is intended to make it a medium for spreading the findings of research in respect to backward children or, at least, to bring to the notice of teachers those results which have clear relevance to their work (1954; 1.2, p. 38 ).

Though it is not made explicit, the "change" in "emphases" appears to signal an intention to increase the number of research reports and the "findings" they offer to teachers. Evidence for this shifting focus is provided as early as 2.1, where teachers are again cast as consumers of research and where the original concern for teacher knowledge appears to have slipped into second place:

A main aim of the journal as previously will be to bring to the notice of our readers reports of experimental work, new projects and ideas which are currently being tried out in Australia and New Zealand with slow learning children. $(1955 ; 2.1, \mathrm{np})^{8}$

Despite an early (stated) conviction that " $[t]$ here is of course no absolutely clear cut distinction between" those matters "which have an immediate bearing on the work of special class, school or training centre" and those "which provide information on experimental work, investigations and research" (1957; 3.3, np), such a distinction was quickly drawn and thereafter reinforced. Moreover, teachers may have found the editorial voice somewhat patronizing when it sought to reassure them that what they did, though different, was also important: "A new method of teaching very backward children the early stages of reading ... constitutes research - and very valuable research too - at one level" $(1957 ; 3.3, \mathrm{np})$. This mention of research "levels" 
necessarily raises questions about status and hierarchy: what "level" did the editors have in mind for dassroom-based research? Above, below, or equal to experimental research?

By 1959 (6.1), the editors acknowledge that, originally, The Slow Learning Child "was a journal for teachers of backward and sub-normal children," but that:

[s] ince that time, the journal has addressed itself to a much wider educational and psychological field - to teachers as before, but also to psychologists, research workers, students, administrators, social workers and all others interested in slow learning whatever its cause may be.

In 6.1, the relative merit of teachers on the editors' hierarchy of professional value may be inferred from a comment that many "prominent educationists have progressed from the small classroom to distinction in the academic and professional field" (p. 4). However, the editorial hints at some discomfort or concern with the expanding readership, particularly with the journal's move toward international status, and seeks to reassure teachers:

It will still, however, be the aim of the Journal to maintain close association with the classroom and with the teacher; and, by a judicious interpretation of research results and through discussions of methods and treatment, to narrow the gap between research findings and actual practice in the school. $(1959 ; 6.1$, p. 3$)$

Something fundamental seems to have happened between 1957, when the editors insisted that there was "no absolutely clear cut distinction between" $(3.3, \mathrm{np})$ practice and research, and this editorial in 1959 that points to a "gap" between the two and offers to help teachers close that gap by "a judicious interpretation of research results"; apparently, teachers were not only no longer considered to be producers of research knowledge, but were thought to need help in making sense of it. The transformation, of course, was gradual, and not completed by 1959. In 1968, editors were still encouraging teachers to produce classroom-based research: "Research for The Slow Learning Child need not be highly formalised. Class-room enquiry is very welcome" $(14.3$, p. 130). But a sea change appears to have occurred - a change that was made explicit as the journal began its second decade: 
This journal aims to increase its experimental content, while at the same time retaining sufficient of the descriptive to satisfy those who are not statistically and experimentally sophisticated. Over the years, we have been more descriptive than experimental; but, evolving with the educational times, we must now change. $(1964 ; 11.1$, p. 2$)$

The inference here, we believe, is that teachers "are not statistically and experimentally sophisticated." Some residual concern for the research-challenged continues through the 60's, related, probably, to a steady increase both in calls for and publication of experimental research. So, for example, the editors report in 1967 that "[e]ducational and psychological research is growing in Australia, but there are inadequate facilities for its reporting and collation." As a result, they introduce a section for reports of current research which they believe will be of great interest, "provided the research is not too esoteric" (13.3, pp. 130-31). A peculiar editorial comment in 1970 finally makes the identity of the unsophisticated clear:

This issue of the journal covers many small details and has many graphs concerning very small numbers. This may be a little strange to teaching colleagues. They will, however, accept that much research has to deal with small numbers. (17.2, p. 67)

Beginning in the late 60's and continuing through the 70 's and 80 's, the movement toward research and away from practice accelerated. An editorial in 1974: "Twenty years ago, this journal was just about completely 'classroom' and teaching technique.... Readers will now see much more statistical sophistication" (20.3, p. 130). In addition, a tone of urgency entered the editors' calls for experimental work. At first, it appears that the need for Australian research was most pressing:

... this is an Australian journal and it is important that articles by Australian authors appear in significant numbers (1967; 14.1, p. 2);

Australia is very young, but it is technologically relatively advanced, and ought to be the scene of research as prolific as its growth and as lucid as its sunlight. $(1968 ; 14.3$, p.130)

But by a decade later, in keeping with the journal's move toward a global readership, the call was no longer local: 
An increase in the number of empirical studies of parents and families of handicapped children is urgently required $(1979 ; 26.1$, p. 2$)$;

Establishing a sound empirical basis for educational decision making has high priority in special education (1981; 28.3, p. 154);

A persistent theme in many of the manuscripts submitted to The Exceptional Child is the need for more research to provide a data base for rationale decision-making in policy determination and service provi$\operatorname{sion}(1984 ; 31.3$, p. 171$)$;

As state-of-the-art reviews of integration have shown, major areas in urgent need of in-depth research and development include... (1987; 34.2, p. 83 ).

Once again, we must insist that nothing indicates that the journal's evolution away from the Australian classroom and toward an international research focus was a deliberate attempt to alienate teachers, but it is impossible to deny the shift in concentration. As a recent editor acknowledges, "[i]t started as a journal for teachers and is now very much for academics" (Sigafoos, October 1997, personal communication). An examination of the journal's textual features reveals the effects of this drift toward the professional discourse of educational research.

\section{Form and forum}

A rhetorical forum has physical or material manifestations. Print size, font, white space, graphics, and other layout features carry communicative weight; they "speak" to the reader. For example, the textual accoutrements of research - the tables, charts, figures, and graphs - may draw readers in or hold them out. In the three numbers that comprise the first volume of The Slow Learning Child there are 3 tables, 5 pictures (of children), and no graphs. In comparison, a single number of The International Journal of Disability, Development, and Education in 1997 contains 32 tables, 5 graphs, and no pictures. Interpretation of the statistics displayed in the graphics requires considerable expertise, an expertise developed in graduate school research training.

Likewise, in-text citations and reference lists indicate a journal's degree of intertextuality - its connections to and location among other texts - and therefore provide a gauge of the background knowledge required to make full sense of the conversation taking place in the forum. Articles in the journal's first volume (1954) 


\begin{tabular}{|l|l|l|l|l|l|l|l|l|l|l|l|l|l|l|l|}
\hline $\begin{array}{l}\text { Volume } \\
\text { (vear) }\end{array}$ & $\begin{array}{l}1 \\
1054\end{array}$ & 4 & 7 & 10 & 13 & $\begin{array}{l}16 \\
19.9\end{array}$ & 19 & 22 & 25 & $\begin{array}{l}28 \\
1981\end{array}$ & 31 & 34 & 37 & 40 & $\begin{array}{l}43 \\
1990\end{array}$ \\
\hline $\begin{array}{l}\text { \# authors per } \\
\text { article }\end{array}$ & 1 & 1.2 & 1.3 & 1 & 1.2 & 1.4 & 1.1 & 1.4 & 1.6 & 1.5 & 1.7 & 2.6 & 1.8 & 2.5 & 3.4 \\
\hline $\begin{array}{l}\text { \# references } \\
\text { per article }\end{array}$ & 5.7 & 8.4 & 1.7 & 6 & 9.3 & 7.4 & 13 & 16 & 25.6 & 17.4 & 15.5 & 20.8 & 20.6 & 27.8 & 40.4 \\
\hline $\begin{array}{l}\text { \# words per } \\
\text { title }\end{array}$ & 6.1 & 7.4 & 6.8 & 11.2 & 9.8 & 7.2 & 10.5 & 8.6 & 15 & 13.6 & 9.1 & 12.8 & 11.6 & 13.6 & 11.4 \\
\hline $\begin{array}{l}\text { \# pages per } \\
\text { journal }\end{array}$ & 44 & 62 & 63 & 6.2 & 62 & 62 & 62 & 62 & 58 & 57 & 74 & 77 & 84 & 77 & 76 \\
\hline $\begin{array}{l}\text { \# pages per } \\
\text { article }\end{array}$ & 6.6 & 8.4 & 5.3 & 8.8 & 7.4 & 10.4 & 6.6 & 11 & 11.8 & 9.1 & 8.5 & 11.1 & 12.3 & 11.5 & 12.2 \\
\hline
\end{tabular}

Table 1: Variations in the journal, 1954-1996

average 5.7 references; by contrast, in Volume 43 (1997), there is an average of 40.4 references per article, and overwhelmingly they point the reader to research literature. Clearly, the anticipated reader is one conversant with a highly specialized discourse. Other variations can be seen in Table 1.

The numbers in Table 1 are revealing, but they only tell part of the story. For instance, the increase in average number of words per article title may suggest a move toward greater clarity through extra detail, but articles in 1954 had titles such as "Help for Parents of Subnormal Children" (1.1) and "Creative Activities for Backward Children" (1.2), which suggest that their discussion might be accessible to the layperson, while titles in more recent numbers invite the research initiate only: "Database Problem Behavior: A Literature Retrieval System for Professionals Dealing with Problem Behaviors of Individuals with Intellectual Disabilities" (43.3), and "Review of Research on Parent Training for Parents with Intellectual Disability: Methodological issues" (44.2).

\section{Reading the marks of culture: Some conclusions}

Our discussion so far has described the evolution of the journal from The Slow Learning Child to The International Journal of Disability, Development, and Education. We have considered the textual artefact, held it up and turned it this way and that, in an effort to understand its origins, its development, its use as a tool within the community it served. We have considered the ways in which the journal's past has left marks on the text, as a tool will offer evidence of hand and use. We have noted in particular three clear marks: an early insistence on teacher participation that was followed by a gradual diminishment in calls for classroom-based knowledge, a shift toward valuing experimentally produced knowledge over practitioners' knowledge, and a steady slide away from the Australian classroom toward international academic institutions. But we have not yet addressed a question we posed near the start of this 
article: Why did this happen? Why did a genre that appeared initially to be designed in large part for the specific needs of the Australian classroom practitioner become instead an international research journal?

Broadly stated, two possibilities exist: either teachers were not engaged in anything resembling classroom-based research, and thus had nothing to report, or the forum created by the journal was not one which teachers found welcoming. We believe the latter explanation is more likely, and offer this comment from Berkenkotter and Huckin (1995) in support of our belief:

It is important to keep in mind that such texts [disciplinary forums] do not spring out of a meeting of the minds alone, but also out of the material conditions of academic culture. These conditions, as most of us know, involve a system of rewards that hinge on publication and national recognition. (p. 82)

As we said at the start, we see the familiar tension between educational practice and educational research at work in the journal's development. We believe the original editors had egalitarian motives. They wished to create a local forum in which people with similar interests but different approaches could share their knowledge to mutual benefit. They wished to bring Australian teachers and researchers together into a single community. But as early as the first volume the desire for a broader, more specialized audience is evident. The reason for this, we believe, is in large part due to the fact that the university-based academics who sponsored the journal and directed its development did so in the context of, to use the Berkenkotter and Huckin phrase cited above, "the material conditions of academic culture." The forum shaped by the journal was a "linguistic market" (Bourdieu, 1993) as well as a site for the exchange of ideas. Such markets occur, Bourdieu explains, "whenever someone produces an utterance for receivers capable of assessing it, evaluating it and setting a price on it" (p. 79). The university market trades in grants, prestige publication, international recognition, and other signs of academic success. As a rule, academics welcome the opportunity to publish in a journal that has more than local or national circulation, and an editorial in 1967 offered that chance: "The Slow Learning Child ... constitutes a vehicle whereby Australian research workers in this field can reach a wider international audience" (14.1, p. 3). We suggest that the language of experimental research fetches a higher "price" within that market (or did, at least, in the field of special education during the period we have studied). 
Researchers, especially those concerned with experimental, quantitative research in an international forum, must move away from the particular toward the general in their search for comprehensive knowledge, for standard deviations, for generalizability, for means and medians, for control groups, for dependent and independent variables, for replicability, for representative samples. To produce such knowledge requires a specialized discourse and a rhetorical forum that will elicit and accommodate the appropriate genres. In a sense, then, the journal did not move away from teachers so much as toward an international community of researchers.

While this may explain why the journal kept and even increased its universitybased membership, it does not sufficiently account for the loss of (or failure to entice) the practitioners that the original editors hoped would become members of the discourse community. Why did teachers not follow as the journal moved toward the more specialized and widely dispersed audience? Are they, as is sometimes claimed, anti-research or anti-intellectual? Do teachers thus miss out on the lessons they might learn from research journals, or do those journals, however inadvertently, bar their entry?

We suspect that the movement away from the local concerns of Australian schools to the necessarily broader and universalized concerns shared by university-based researchers throughout the English-speaking world drove teachers away. Curricula, government policies, public attitudes, teaching conditions, materials - all of that, and more, vary from place to place, even within countries; once national borders are crossed, specific teaching practices are understandable only with considerable explanation, and practitioners may have found the resulting move toward abstraction and generalization of little use in the day-to-day reality of their classrooms. Teachers are concerned primarily with the particulars of their classrooms, the detail of day-to-day practice, their everyday reality. Knowledge and rhetorical action for them is necessarily local, contingent, situated in highly specific settings and circumstances.

The initial years of the journal did offer much of value to teachers - some of it written by teachers - and it might well have become a forum for teacher concerns. But the inexorable slide away from the classroom and the increasingly opaque discourse of experimental research probably discouraged teachers from participating. That discourse, which includes a highly specialized vocabulary, a largely implicit set of values and beliefs, and an intricate intertextual web, is open to members only. A failure to seek membership does not indicate an anti-intellectual bias by teachers; more likely, it signals a choice to produce and pursue a different knowledge, one more local, applicable, practical, and immediate. 
As with other forms of archaeology, our dig into the rhe torical past has relied on inference, speculation, and hunch, and yet our conclusions fit with our experience of teachers and teachers-in-training, many of whom are impatient with what they see as obscure and irrelevant educational research. The text we have examined and described grew from one dedicated to the creation of a forum for an edectic community comprised of researchers and practitioners engaged in knowledge-making. Over time, it was transformed into an extremely esoteric forum restricted to a community of those able to deploy a highly specialized discourse to produce a specific type of knowledge - a discourse and knowledge at odds with the language and thought of practitioners. We believe that teachers abandoned that community because, ultimately, it offered them little or no advantage.

If teachers and researchers are to talk "in mutual support," rather than "against each other," as Bazerman notes in the epigram at the start of this article, they will have to define shared motives and shape a forum, a linguistic market, where talk about classroom practice is valued as highly as talk about research.

\section{Acknowledgment}

The authors would like to thank Janet Giltrow and Graham Smart for their comments on an earlier version of this article, and two anonymous reviewers for their feedback on a more recent version.

\section{Notes}

1. This definition of genre contrasts with the more common notions of genre that come from, for example, literary studies (poetry, the novel, drama, and their sub-genres) or business communications (memo, business letter, annual report, and so on). Such definitions focus on repetition in the physical text, while the broader definition used here seeks to link textual regularity with patterns in a community's social action (see Paré and Smart, 1994).

2. The study reported here grew from a graduate course assignment that asked students to imagine that they were archaeologists in the distant future sifting through the ruins of a library. They were encouraged to examine a number of samples of a repeated text and to treat the text as a cultural artefact from which to draw inferences about the circumstances of its production and use, its purposes and likely consequences, the relationships between its writers and readers, and other aspects of the culture within which the text had originally 
come to life and circulated. The use of "archaeology" is more than a metaphor, however, since our method owes something to the deconstructive archaeology of Foucault (especially The Archaeology of Knowledge and the Discourse on Language), which seeks to uncover the development of "discursive formations" in order to examine the workings of discourse in the making of knowledge. The first author taught the course and the second author was a student whose initial research inspired this article.

3. Academic journals are actually sites and occasions of multiple genres: editorials, articles, book reviews, research reports, calls for papers, point/counterpoint sections, and so on, as well as the regular surface, fax, and electronic communications between editors and reviewers, editors and authors, and reviewers and authors. As such, journals might more accurately be called genre "sets," the term Devitt (1991) uses to describe a collection of repeated and related texts used within a professional community. Since this article is concerned less with the component parts of the journal than with the text as a whole, we refer to the full magazine as a genre.

4. Inaugural editorials are a hardy genre and display similar characteristics over time and across disciplines. Their chief rhetorical move is designed to clear a knowledge-making space for the community they serve or imagine. Typically, the claim is made that a "forum" is needed for a particular, specialized discussion - one not occurring or possible in extant journals. (See Porter, 1992, for a helpful exploration of the term "forum.") The claim is generally made on disciplinary, national, ideological, or epistemological grounds: "we need to talk about education/Canadian/progressive/theoretical/etc. issues." Our time spent leafing through volume 1 , number 1 editorials also showed us that the move from newsletter to journal happens with some regularity.

5. All references to the journal will follow this pattern: year; volume, number, page; thus, 1.1, p. 1 refers to Volume 1 , Number 1 , page 1 of the inaugural issue in 1954; $\mathrm{np}$ is used where no page is identified or identifiable.

6. An interesting cultural footnote: in parentheses following this encouragement to "modest" teachers, the editor has written " $[t]$ he use of the masculine form in this paragraph is used solely for clarity. The description is probably even more applicable to women teachers" (1960; 6.3, p. 131). We can understand why the description might be considered "more applicable to women," because of their presumed greater "natural" modesty, but we wonder how use of the masculine pronoun increases the paragraph's clarity. 


\section{A note in a 1967 editorial (14.1) suggests some concern with this international} trend: "The Slow Learning Child' values the flow of articles which we have received from overseas sources and we welcome two Scandinavian contributions from Drs. Emanuelsson and Nilsson in the current issue. Nevertheless, this is an Australian journal and it is important that articles by Australian authors should appear in significant numbers" (p. 2). However, the editorial appears to deplore the shortage "of serious work - at least at the level of research - that is going on in [Australia]" (p. 2) rather than the loss of an Australian context or background. As such, it seems to us an example of the trend of the journal toward research and away from practice. This reading is strengthened by a similar call for Australian research in the editorial of 14.3 (1968), and a lament that one research report "is the only Australian contribution in this issue. We could do with more" (p. 130). The scolding tone here echoes earlier expressions of concern about the shortage of classroombased research. In both cases, the regret is that a local (i.e., Australian) community appears unable or unwilling to create the type and quantity of discourse necessary to sustain the journal originally imagined by the editors.

8. In this first anniversary issue, there is a curious editorial comment that we suspect may reflect a common belief among participants in the immutability of genres: "This first number of the second volume of 'The Slow Learning Child' sees our journal in what we hope, is its permanent form" (1955; 2.1, np).

9. A similar denial of difference is made in a 1967 editorial, where it is reported that journal subscribers "can be broadly classified into one of two groups, namely, practising classroom teachers and students of special education - not that these two categories are necessarily mutually exclusive." Nonetheless, the editorial goes on to indicate that "[b]oth categories are nicely represented" (13.3, p. 130) in the issue by articles that take either an experimental or a practical approach.

\section{REFERENCES}

Bakhtin, M.M. (1981). Discourse in the novel. In M. Holquist (Ed.) and C. Emerson and M. Holquist (Trans.), The dialogic imagination (pp. 259-422). Austin: University of Texas Press. 
Bakhtin, M.M. (1986). The problem of speech genres. In C. Emerson \& M. Holquist (Eds.) and V.W. McGee (Trans.), Speech genres and other late essays (pp. 60102). Austin: University of Texas Press.

Bazerman, C. (1994). Constructing experience. Carbondale, IL: University of Southern Illinois Press.

Bazerman , C. (1988). Shaping written knowledge: The genre and activity of the experimental article in science. Madison: University of Wisconsin Press.

Berkenkotter, C. and T.N. Huckin. (1995). Genre knowledge in disciplinary communication: Cognition/culture/power. Hillsdale, NJ: Erlbaum.

Bourdieu, P. (1993). Sociology in question ( R. Nice, Trans.). London: Sage Publications. (Original work published 1984)

de Certeau, M. (1984). The practice of everyday life. (Trans. Steven Rendall). Berkeley: University of California Press.

Devitt, A. (1993). Generalizing about genre: New conceptions of an old concept. College Composition and Communication, 44, pp.573-86.

Foucault, M. (1972). The archaeology of knowledge and the discourse on language. Trans. A.M. Sheridan Smith. New York: Pantheon-Random.

Freedman, A. and P. Medway (Eds.). (1994a). Genre and the new rhetoric. London: Taylor \& Francis.

Freedman, A. and P. Medway (Eds.) (1994b). Learning and teaching genre. Portsmouth, NH: Boynton/Cook Heinemann.

Giltrow, J. (1994). Genre and the pragmatic concept of background knowledge. In A. Freedman and P. Medway (Eds.). Genre and the new rhetoric (pp. 155-178). London: Taylor \& Francis.

Herrington, A. (1989). The first twenty years of Research in the teaching of English and the growth of a research community in composition studies. Research in the teaching of English, 23, pp. 117-138.

Miller, C.R. (1994a). Genre as social action. In A. Freedman and P. Medway (Eds.). Genre and the new rhetoric (pp. 23-42). London: Taylor \& Francis.

Miller, C.R. (1994b). Rhetorical community: The cultural basis of genre. In A. Freedman and P. Medway (Eds.). Genre and the new rhetoric (pp. 67-78). London: Taylor \& Francis. 
Paré, A. and Smart, G. (1994). Observing genres in action: Towards a research methodology. In A. Freedman and P. Medway (Eds.). Genre and the new rhetoric (pp. 146-54). London: Taylor \& Francis.

Porter, J. E. (1992). Audience and rhetoric: An archaeological composition of the discourse community. Englewood Cliffs, NJ: Prentice-Hall.

Schryer, C. F. (1994). The lab vs. the clinic: Sites of competing genres. In A. Freedman and P. Medway (Eds.). Genre and the new rhetoric (pp. 105-124). London: Taylor \& Francis.

Sigafoos, J. (October 1997). Personal e-mail communication. 